\title{
SISTEM INFORMASI MONITORING DATA DEBIT DAERAH IRIGASI DENGAN METODE PENGUKURAN DEBIT SESAAT (Studi Kasus : Bendungan Batujai Kecamatan Praya Barat Kabupaten Lombok Tengah, NTB)
}

\author{
Fendi Prayadi ${ }^{1}$ Khairul Imtihan $^{2}$, Hairul Fahmi ${ }^{3}$ \\ ${ }^{1}$ Teknik Informatika, STMIK Lombok \\ ${ }^{2}$ Sistem Informasi, STMIK Lombok \\ 3Teknik Informatika, STMIK Lombok \\ Jln. Basuki Rahmat No.105 Praya Lombok Tengah 83511 \\ ${ }^{1}$ fendi.prayadi25@yahoo.com ${ }^{2}$ khairulimtihan31@gmail.com ${ }^{3}$ iroel.ami@gamil.com,
}

\begin{abstract}
Abstrak
Daerah Irigasi (D.I) Batujai secara administratif berada di bawah lingkup Unit Pelaksana Teknis (UPT). Daerah Aliran Sungai (DAS) Batujai adalah Instansi Pemerintah yang bergerak dibidang Energi Sumber Daya Mineral (ESDM) dalam bidang Pengelolaan Sumber Daya Air (PSDA) Nusa Tenggara 1 Irigasi Pertanian. Pendistribusian air D.I Batujai menggunakan sistem buka tutup pintu pengambilan sadap dan pintu bagi, pendataan laporan debit dengan metode debit sesaat yang dilakukan secara manual oleh Tugas Pembantu Oprasi dan Pemeliharaan (TP-OP) tanpa adanya monitoring oleh Juru Pengairan (Jupeng).

Dalam perencanaan kebutuhan air irigasi, jumlah air (Debit) yang tersedia di Bendungan Batujai digunakan sebagai debit untuk realisasi perencanaan Rencana Tata Tanam (RTT) yang diharapkan mampu menyediakan pendistribusian kebutuhan air untuk pertanian Musim Taman Satu, Dua dan Tiga (MT I, II, III) dan keperluan kegiatan manusia lainnya dalam waktu jangka panjang. Pendistribusian air D.I Batujai dilakukan dengan pengukuran debit menggunakan metode debit sesaat yang disesuaikan dengan tabel uraian fase kebutuhan air pada tanaman yang telah ditetapkan oleh PSDA Nusa Tenggara 1 namun, kurangnya monitoring dalam pendistribusian dan pemberian debit ke areal tanam yang dilakukan oleh Tugas Pembantu Oprasi dan Pemeliharaan (TP-OP), Juru Pengairan, Pengamat Irigasi menyebabkan sering terjadinya penggunaan air secara berlebihan yang dilakukan petani D.I Batujai setempat. Pembuatan laporan debit yang masih menggunakan sistem manual (tulis tangan) juga menyebapkan kurang efektif dan efisien alokasi ketersediaan dan pendistribusian air dikarnakan sering terjadinya kesalahan dan manipulasi data debit, sehingga diperlukan sistem yang berbasis komputer untuk memonitoring data debit daerah irigasi Batujai.

Metode penghitungan debit menggunakan metode pengukuran debit secara langsung (debit sesaat), untuk perancangan sistem monitoring menggunakan metode SDLC (Sistem Development Life Sysle), tujuan penelitian ini adalah merancang dan menghasilkan sistem informasi monitoring data debit daerah irigasi pada bendungan batujai yang akan mempermudah dalam hal monitoring pendistribusian debit dan laporan debit yang lebih cepat untuk melaporkan debit yang direalisasikan oleh petugas yang disesuaikan denga rencana kebutuhan air.
\end{abstract}

Kata kunci : Sistem Informasi Monitoring, Debit Sesaat, Batujai, PHP, MySql. 


\section{Pendahuluan}

Teknologi sangat diperlukan untuk mempermudah atau memaksimalkan suatu kinerja. Salah satu teknologi yang berkembang saat ini adalah teknologi sistem informasi alokasi ketersediaan dan pendistribusian debit (jumlah air) yang efektif dalam pendistribusian debit dan efisien dalam pemberian debit sebagai salah satu usaha meningkatkan produktifitas pertanian dan ketahanan pangan Indonesia khususnya Provinsi Nusa Tenggara Barat Kabupaten Lombok Tengah, pemenuhan kebutuhan akan air sangat berperan penting. Dalam pendistribusian air di Daerah Irigasi (D.I) Batujai, kenyataannya seringkali terdapat pendistribusian air yang kurang sesuai dengan uraian fase kebutuhan air pada tanaman yang telah ditetapkan oleh PSDA Nusa Tenggara 1 yang dipadukan dengan Rencana Tata Tanam (RTT) tahunan. Pada areal pertanian yang dekat dengan bangunan Intake cenderung mendapatkan air yang berlebihan, sedangkan pada areal pertanian yang jauh dengan bangunan Intake cenderung kekurangan air hingga menyebabkan gagal panen.

Dalam perencanaan kebutuhan air irigasi, jumlah air (Debit) yang tersedia di Bendungan Batujai digunakan sebagai debit untuk realisasi perencanaan Rencana Tata Tanam (RTT) yang diharapkan mampu menyediakan pendistribusian kebutuhan air untuk pertanian Musim Taman Satu, Dua dan Tiga (MT I, II, III) dan keperluan kegiatan manusia lainnya dalam waktu jangka panjang. Pendistribusian air D.I Batujai dilakukan dengan pengukuran debit menggunakan metode debit sesaat yang disesuaikan dengan tabel uraian fase kebutuhan air pada tanaman yang telah ditetapkan oleh PSDA Nusa Tenggara 1 namun, kurangnya Monitoring dalam pendistribusian dan pemberian debit ke areal tanam yang dilakukan oleh Tugas Pembantu Oprasi dan Pemeliharaan (TP-OP), Juru Pengairan, Pengamat Irigasi menyebapkan sering terjadinya pencurian air yang dilakukan petani D.I Batujai setempat. Pembuatan laporan debit yang masih menggunakan sistem manual (tulis tangan) juga menyebapkan kurang efektif dan efisien alokasi ketersediaan dan pendistribusian air dikarnakan sering terjadinya kesalahan dan manipulasi data debit.

Sehingga diperlukan sistem yang berbasis komputer untuk memonitoring data debit daerah irigasi Batujai. Metode penghitungan debit menggunakan metode pengukuran debit secara langsung (debit sesaat), untuk perancangan sistem monitoring menggunakan metode SDLC (Sistem Development Life Sysle), tujuan penelitian ini adalah merancang dan menghasilkan sistem informasi monitoring data debit daerah irigasi pada bendungan batujai yang akan mempermudah dalam hal monitoring pendistribusian debit dan laporan debit yang lebih cepat untuk melaporkan debit yang direalisasikan oleh petugas yang disesuaikan denga rencana kebutuhan air.

\section{Tinjuan Pustaka}

Patirajawane (2015) dalam penelitiannya "Studi Optimasi Distribusi Pemanfaatan Air Di Daerah Irigasi Melik, Kabupaten Jombang Menggunakan Program Linear". Untuk mengoptimalkan debit yang berlebih pada Daerah Irigasi Melik sehingga terdapat keseimbangan pada neraca air. Kelebihan debit pada D.I Melik tidak akan meningkatkan hasil pertanian dikarenakan pada MT III kesuburan tanah menurun untuk ditanami padi atau jagung kecuali dengan penambahan lahan pertanian atau peternakan ikan.

Rudianto (2014) dalam penelitiannya "Sistem Informasi Monitoring Dan Evaluasi (Simonev) Keberlanjutan Kelembagaan Himpunan Petani Pengguna Air (HIPPA)". Sistem informasi melakukan proses monitoring dan evaluasi terhadap kelembagaan HIPPA dapat dilakukan secara cepat, maka peneliti beranggapan perlu dikembangkan adanya suatu sistem informasi yang dapat melakukan pengolahan data hasil monitoring dan evaluasi secara on-line. Agar sistem informasi dan monitoring ini dapat diterapkan secara optimal, maka perlu adanya pelatihan pemanfaatan teknologi internet untuk para petani. Dalam melakukan monitoring dan evaluasi dapat dilakukan secara online sehingga semua update data, dapat dilakukan secara otomatis.

Biahimo (2014) dalam penelitiannya "Analisis Efisiensi Penyaluran Air Irigasi Dengan Sistem Informasi Geografis Bendungan Lomaya Kabupaten Bone Bolango Provinsi Gorontalo". Menyajikan informasi tentang efisiensi irigasi secara spasial. Untuk meningkatkan efisiensi penyaluran pada daerah irigasi Lomaya ini sebaiknya pemerintah melakukan perbaikan pada saluran-saluran yang kurang baik kondisi fisiknya. Selain itu menganjurkan kepada masyarakat agar tidak membuang sampah di saluran dan menjaga saluran agar tidak dipenuhi tanaman yang bisa menghambat ketersediaan air. Efisiensi penyaluran total pada daerah irigasi Lomaya bendungan Lomaya kabupaten Bone Bolango provinsi Gorontalo adalah sebesar 
$50,41 \%$, artinya irigasi ini masih kurang baik penyalurannya. Daerah layanan pada irigasi ini mengalami kekurangan sebesar 101,07 hektar.

Indarto (2010) dalam penelitiannya "Desain Fitur Dan Implementasi Sistem Informasi Daerah Irigasi (SIDI) Sampean". Penelitian ini untuk mengembangkan Sistem Informasi Daerah Irigasi (SIDI) yang berbasis Mapwindow GIS. SIDI diharapkan dapat menjadi tool untuk operasional sehari-hari bagi pengelolaan Daerah Irigasi. Penggunaan OSS-GIS diharapkan dapat memberikan solusi bagi mahalnya biaya software yang harus dialokasikan untuk manajemen irigasi. Penelitian ini telah menghasilkan plug-in SIDI yang berfungsi sebagai alat pendukung operasi dan pemeliharaan Jaringan Irigasi. Implementasi SIDI di lapangan menunjukan bahwa SIDI cukup user-friendly dan memungkinkan pengguna mengakses informasi dalam bentuk peta, skema, tabel dan foto.

\section{Metodologi Penelitian}

\subsection{Metode Pengumpulan Data}

1. Interview, yaitu bertanya langsung kepada narasumber (Pengamat Irigasi, Juru Pengairan dan Juru Pintu Air) untuk mendapatkan informasi tentang cara mengatur pendistribusian air irigasi dalam pengembangan dari pada penulis.

2. Observasi, yaitu melakukan penelitian langsung ke saluran D.I Batujai untuk mengetahui keadaan area lingkungan kerja.

3. Studi literature, yaitu mengunjungi situssitus yang menyediakan pembahasan mengenai sistem informasi pendistribusian air irigasi.

\subsection{Metode Analisis}

Analisis dalam penelitian ini adalah dengan menggunakan analisis SWOT (Strenght, Weakness, Opportunity, and threat ). Dengan metode ini menunjukan kinerja dari UPT DAS Batujai dalam ketersediaan dan pendistribusian air dengan menentukan kombinasi faktor internal dan eksternal. Analisis SWOT membandingkan antara faktor internal, yaitu kekuatan (stregth) dari sistem data debit manual, dan kelemahan (weakness) sistem data debit manual dalam menyediakan dan mendistribusian kebutuhan debit. Factor eksternal yaitu menganalisis peluang (opportunity) petani dalam peningkatkan hasil pertanian dengan sistem data debit manual, dan ancaman (threats) dengan sistem data debit manual dalam mendistribusian kebutuhan debit yang tidak di Monitoring

\subsection{Metode Perancangan}

Metode perancangan yang digunakan pada perancangan sistem informasi Monitoring data debit Daerah Irigasi Batujai ini adalah metode SDLC (System Development Life Cycle) dengan tahapan yaitu tahap perencanaan, analisis kebutuhan, perancangan, implementasi, pengujian dan tahap pemeliharaan.

\subsection{Metode Pengujian Sistem}

Metode pengujian yang digunakan adalah pengujian Black Box Testing dengan pengujian untuk menguji proses perancangan sistem yaitu proses input, proses dan output.

\subsection{Metode Pengukuran Debit Secara Langsung (Debit Sesaat)}

Pengukuran debit di saluran sekunder dan tersier menggunakan metode pengukuran debit secara langsung dengan alat ukur Peilschal dan Drempel dengan rumus sebagai berikut :

$$
\begin{aligned}
& \mathrm{Q}=1,71 \times \mathrm{b} \times \mathrm{h} \\
& \text { Keterangan: } \\
& \mathrm{Q}=\text { debit air } \\
& \mathrm{b}=\text { lebar ambang } \\
& \mathrm{h}=\text { tinggi permukaan air }
\end{aligned}
$$

\section{Hasil dan Pembahasan}

\subsection{Flowmap Sistem}

\subsubsection{Flowmap Sistem Berjalan}

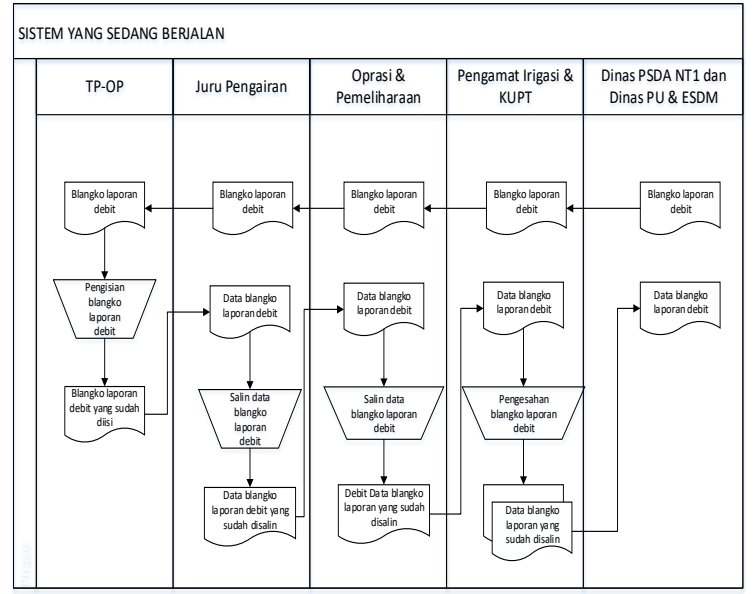

Gambar 4.1 Flowmap Sistem Berjalan

Keterangan Gambar :

1. Sistem informasi pengolahan data debit yang sedang berjalan melibatkan lima entitas yaitu TP-OP JPA, Juru Pengairan, Bagian Oprasi \& 
Pemeliharaan, Pengamat Irigasi \& KUPT dan Dinas PSDA \& Dinas PU ESDM.

2. Pengamat Irigasi memberikan blangko laporan debit kepada Bagian Oprasi \& Pemeliharaan, kemudian Bagian Oprasi \& Pemeliharaan memberikan blangko laporan debit kepada Juru Pengairan, lalu Juru Pengairan memberikan blangko laporan debit kepada TP-OP JPA.

3. Blangko laporan debit diisi oleh TP-OP JPA, setelah pengisian blangko laporan debit selama 15 harian selanjutnya blangko laporan debit TP-OP JPA diserahkan kepada Juru Pengairan untuk disalin dan sebagai arsip. setelah blangko laporan debit TP-OP JPA disalin ke blangko laporan debit Juru Pengairan selanjutnya blangko laporan debit Juru Pengairan diserahkan kepada Bagian Oprasi \& Pemeliharaan untuk disalin ke blangko laporan debit Bagian Oprasi \& Pemeliharaan dan sebagai arsip.

\subsubsection{Flowmap Usulan}

Sistem Informasi Data Debit D.I Batujai sebagai solusi dalam efisiensi pendistribusian air D.I Batujai dan menjaga ketersediaan air untuk musim tanam berikutnya dari faktor kehilangan air yang disebapkan kurangnya monitoring serta kesadaran petani pemakai air D.I Batujai akan uraian fase kebutuhan air untuk tanaman.

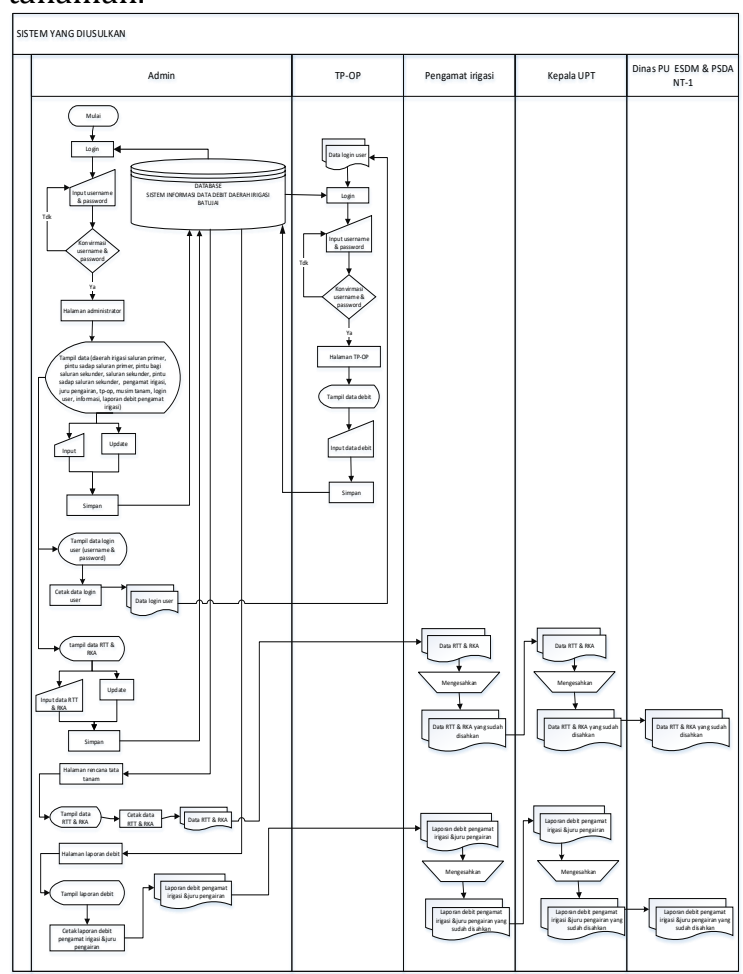

Keterangan Gambar :

1. Admin login input username dan password

2. Sistem mengecek username dan password didatabase.

3. Konfirmasi username dan password benar atau salah

4. Jika username dan password salah maka ulang menginputkan username dan password dan jika benar maka masuk kehalaman Admin

5. Admin Input data daerah irigasi, saluran primer, pintu sadap saluran primer, pintu bagi saluran sekunder, saluran sekunder, pintu sadap saluran sekunder, pengamat irigasi, juru pengairan, tp-op, musim tanam, login user, informasi, laporan debit pengamat irigasi kemudian simpan, dan admin melakukan update jika ada kesalahan atau penambahan data.

6. Tampil halaman admin data user, kemudian data user (username dan password) selanjutnya cetak data user kemdian di serahkan kepada setiap user (TP-OP).

7. Admin menginputkan data rencana tata tanam dan rencana kebutuhan air kemudian disimpan.

8. TP-OP melakukan login input username dan password

9. Sistem mengecek username dan password didatabase.

10. Konfirmasi username dan password benar atau salah

11.Jika username dan password salah maka ulang menginputkan username dan password dan jika benar maka masuk kehalaman Admin

12. TP-OP Input data debit kemudian disimpan lalu akan ditampilkan halaman laporan debit pengamat irigasi dan juru pengairan.

13. Admin mencetak data rencana tata tanam, rencana kebutuhan air, data laporan debit pengamat irigasi dan juru pengairan kemudian diserahkan kepada pengamat irigasi dan KUPT untuk disahkan. Setelah pengesahan maka selanjutnya dikirim ke Dinas PSDA NT-1 dan Dinas PU \& ESDM.

4.2. Perancangan Proses

4.2.1. DFD (Data Flow Diagram)

Gambar 4.2 Flowmap Usulan 


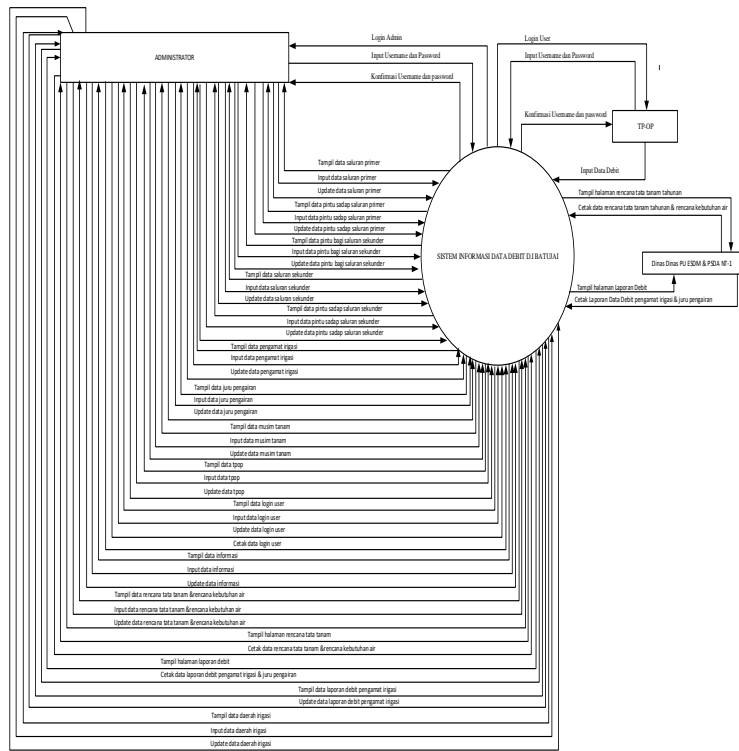

Gambar 4.3 Diagram Konteks Sistem Informasi Data Debit

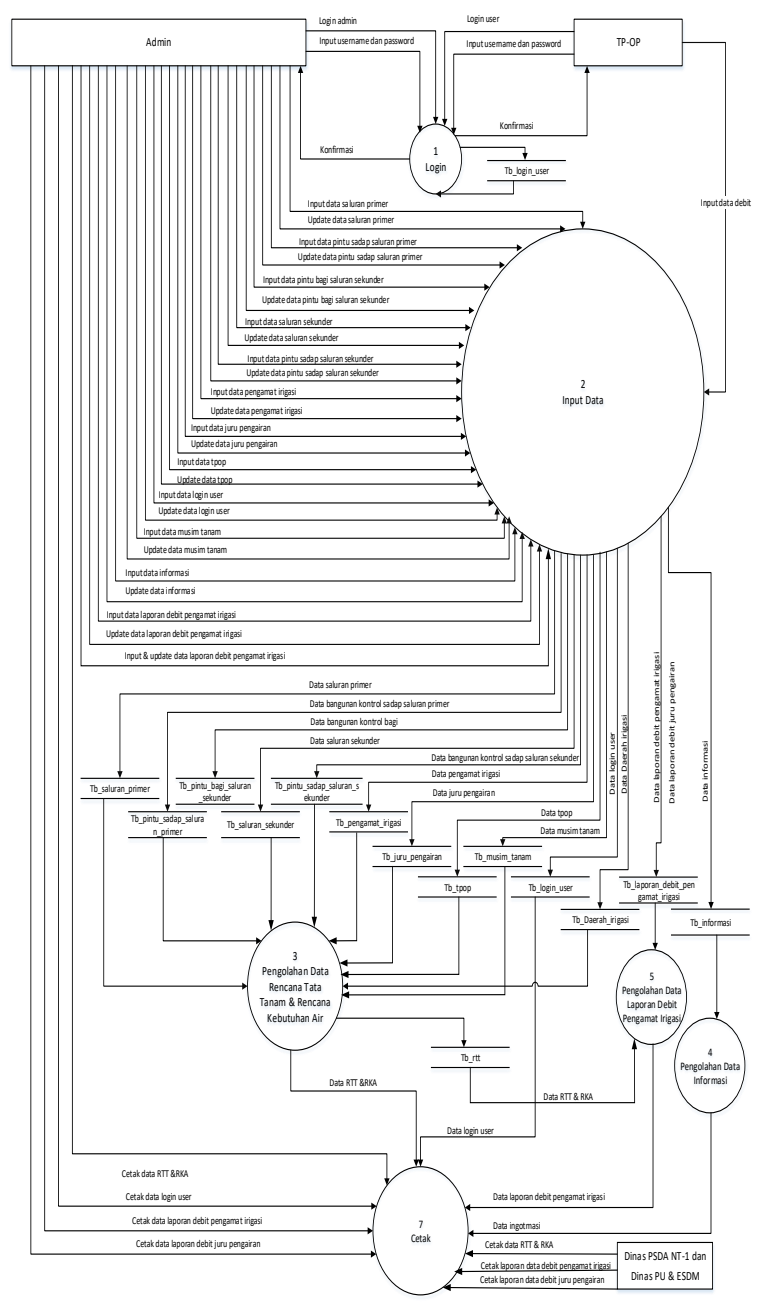

Gambar 4.4 DFD Level 1 Sistem Informasi Data Debit
4.2.2. Perancangan ERD (Entity Relationship Diagram)



Gambar 4.5 ERD (Entity Relationship Diagram)

\subsubsection{Perancangan Struktur Menu}
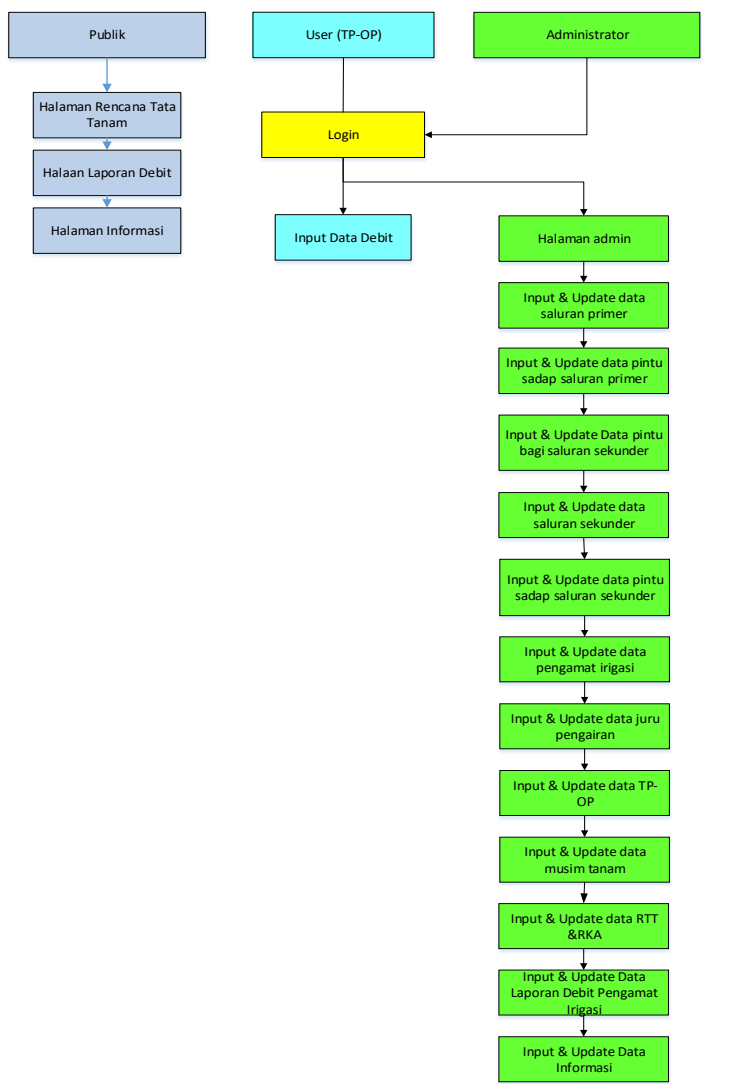

Gambar 4.6 Struktur Menu 


\subsection{Perancangan Interface}

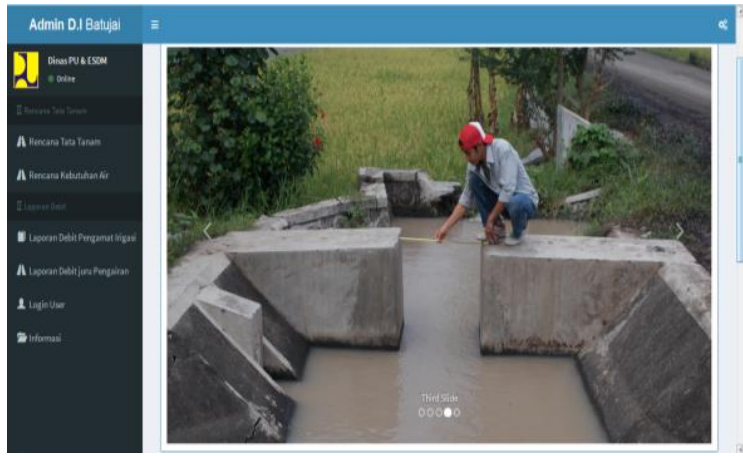

Gambar 4.7 Halaman Utama

Halaman ini berfungsi untuk menampilkan halaman utama dari program, untuk di lihat oleh pengunjung maupun admin ketika membuka Sistem Informasi Data Debit Daerah Irigasi Batujai Dengan Metode Pengukuran Debit Secara Langsung (debit sesaat)

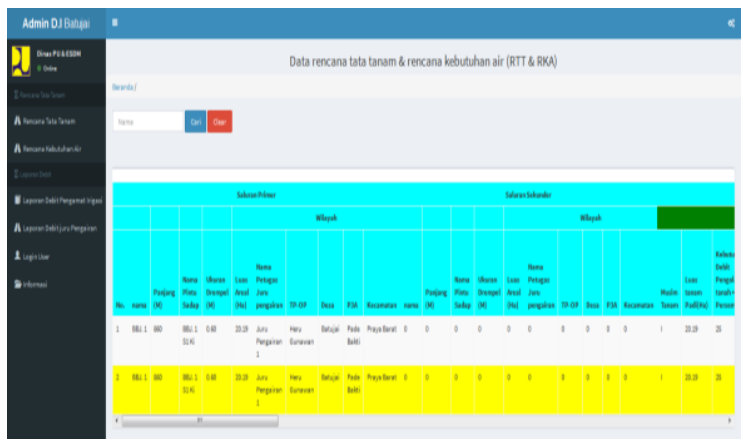

Gambar 4.8 Halaman RTT atau RKA

Halaman ini menjelaskan tentang Rencana Tata Tanam dan Rencana Kebutuhan Air sebagai acuan para petugas D.I Batujai dan P3A/GP3A D.I Batujai. Interface Halaman RTT \& RKA

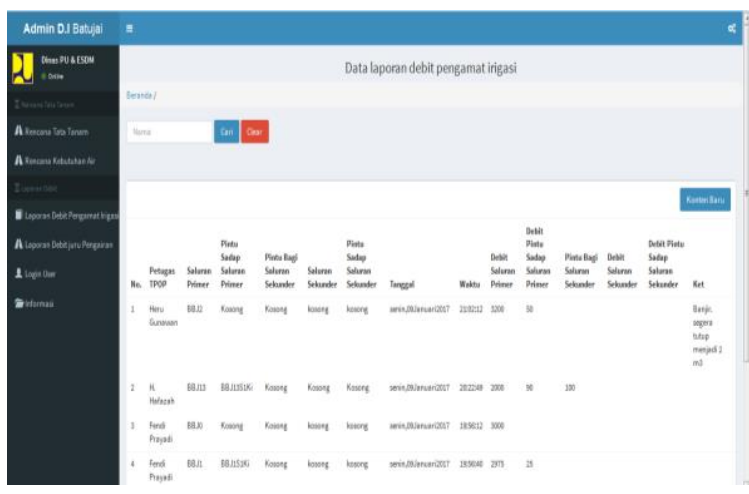

Gambar 4.9 Halaman Laporan Debit Pengamat Irigasi

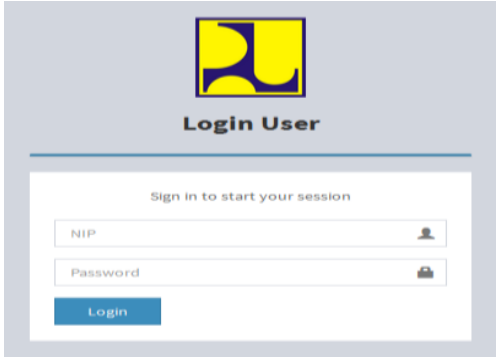

Gambar 4.10 Halaman Login User

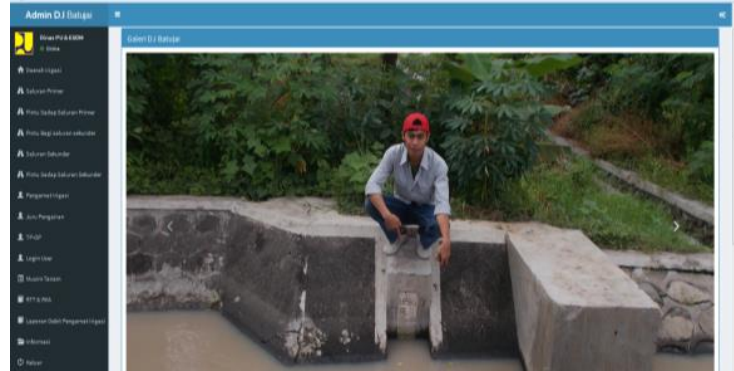

Gambar 4.11 Halaman Data Master

Keterangan Gambar :

Halaman ini menjelaskan tentang data-data master yang akan diinptkan oleh admin. Ada 12 data master yang akan diinputkan admin yaitu data daerah irigasi, data saluran primer, data pintu sadap saluran primer, data pintu bagi saluran sekunder, data saluran sekunder, data pintu sadap saluran sekunder, data pengamat irigasi, data juru pengairan, data TP-OP, data login user, data musim tanam, data informasi.

\section{Kesimpulan dan saran}

\subsection{Kesimpulan}

1. Proses monitoring pendistribusian debit yang efisien dan efektif serta laporan debit yang lebih cepat dalam waktu 1 menit saja dari pada laporan secara manual membutuhkan waktu 15 hari kemudian dikumpulkan. Ketepatan laporan debit yang disesuaikan dengan luas tanam, jenis tanaman, dan fase tanamnya.

2. Untuk mengetahui kebutuhan air pada musim tanam, fase tanam, dan fase pertumbuhan tanaman digunakan rumus (luas tanam x satuan kebutuhan air di sawah (l/det/ha) yang disesuaikan dengan jenis tanaman, fase tanam, dan fase pertumbuhan tanaman $\mathrm{x}$ jumlah hari jenis tanaman, fase tanam, dan fase pertumbuhan tanaman)

3. Keluaran (Output) dari Sistem Informasi Monitoring Data Debit Daerah Irigasi Batujai ini berupa rencana kebutuhan air untuk musim tanam dan laporan debit 
4. Pelaksanaan kegiatan pendistribusian debit yang efisien dan efektif tidak mengalami pemborosan ataupun kehilangan air karena telah ditentukan kebutuhan debit untuk setiap wilayah tanam serta monitoring dilakukan secara online.

\subsection{Saran}

Penelitian perancangan dan pengembangan sistem data debit ke depannya bisa menambahkan metode inflow dan outflow untuk mengetahui persentase kehilangan air.

\section{Daftar Pustaka:}

Andri Kristanto, 2008, Perancangan Sistem Informasi dan Aplikasinya, Gava.

Abdul Kadir, 2003, Pengenalan Sistem Informasi, Andi, Yogyakarta.

Dr. Azhar Susanto, MBus, Ak. 2004. Sistem Informasi Manajemen Konsep dan Pengembangannya. Lingga Jaya. Bandung.

Jogiyanto. 2005. Analisis dan Desain Sistem Informasi. Yogyakarta: Penerbit Andi.

Yakub. 2008. Sistem Basis Data Tutorial Konseptual. Graha Ilmu. Yogyakarta

Peranginangin, Kasiman. 2006. Aplikasi Web dengan PHP dan MySQL. Yogyakarta: Penerbit Andi.

Dinas PSDA NT-1. 2015. Pelatihan operasi jaringan irigasi dan pengisian blangko operasi.

Agus Sumadiyono, jurnal, 2012, analisis efisiensi pemberian air di jaringan irigasi karau kabupaten barito timur provinsi kalimantan tengah.

Abdul Rouf, Jurnal, 2014, Pengujian Perangkat Lunak Dengan Menggunakan Metode White Box Dan Black Box, Stmik Himsya Semarang.
Mochamad Rangga A P, 2012, studi efisiensi pemberian air irigasi desa kutoharjo, kecamatan pati, kabupaten pati, jawa tengah, Universitas Negeri Semarang.

Yurizal Biahimo, 2014, analisis efisiensi penyaluran air irigasi dengan sistem informasi geografis bendungan Lomaya Kabupaten Bone Bolango Provinsi Gorontalo, Universitas Sam Ratulangi Manado.

Fauriza Patirajawane, 2013 studi optimasi distribusi pemanfaatan air di Daerah Irigasi Melik Kabupaten Jombang dengan menggunakan program linear, Universitas Brawijaya.

Indarto, 2010, Jurnal, desain fitur dan implementasi sistem informasi daerah irigasi (studi kasus: daerah irigasi sampean baru), Kampus Tegalboto, Jember.

Ahmad Susan Pardiansyah. "Audit Tata Kelola Teknologi Informasi Program Studi Sistem Informasi Sekolah Tinggi Manajemen Informatika Dan Komputer (STMIK) Lombok Menggunakan." IJSE-Indonesian Journal on Software Engineering 1.1 (2015).

Maulana Ashari. "Audit Information Technology (IT) Governance Pada Sekolah Tinggi Manajemen Informatika Dan Komputer (STMIK) Lombok Menggunakan Framework COBIT 4.1." Bianglala Informatika 3.2 (2015).

Wire Bagye. "Analisis Tingkat Kematangan Sistem Informasi Akademik Menggunakan Framework COBIT 4.1 (Studi Kasus: STMIK Lombok)." Speed-Sentra Penelitian Engineering dan Edukasi 8.1 (2016). 